\title{
The environmental impact of solid-state materials working in an active caloric refrigerator compared to a vapor compression cooler
}

\author{
Ciro Aprea $^{1}$, Adriana Greco ${ }^{2}$, Angelo Maiorino ${ }^{1}$, Claudia Masselli ${ }^{*}$ \\ ${ }^{1}$ University of Salerno, Via Giovanni Paolo II 132, 84084 Fisciano (SA), Italy \\ ${ }^{2}$ University of Naples "Federico II", P. le Tecchio 80, 80125 Naples, Italy
}

Corresponding Author Email: cmasselli@unisa.it

https://doi.org/10.18280/ijht.360401

Received: 29 August 2018

Accepted: 11 November 2018

Keywords:

caloric refrigeration, Environmental Impact, TEWI analysis, solid-state materials, vapor compression, electrocaloric, elastocaloric, magnetocaloric

\begin{abstract}
Caloric refrigeration is an emerging class of cooling technologies based on caloric effects detected in ferro-caloric solid-state materials. Depending of the nature of the driving field, it is possible distinguishing four main caloric refrigerations: magnetocaloric, electrocaloric, elastocaloric and barocaloric. Therefore, caloric refrigeration is based on solid-state materials, unlike vapor compression, nowadays still the most diffused cooling technique, whom employs fluids as refrigerants. Solid-state materials do not provide a direct contribution in global warming, since they do not disperse in the atmosphere, but only an indirect impact is registered when they are employed as refrigerants in cooling systems. On the other side, a vapor compression plant is characterized by both direct and indirect contributions to global warming. The main parameter to evaluate global warming impact and carbon-dioxide emissions coming out from a cooler is the Total Environmental Warming Impact (TEWI) index, which accounts both the direct and indirect contributions produced. In this paper a numerical $\triangle T E W I$ analysis is presented, comparing the environmental impact of a caloric refrigerator, operating with different caloric materials, with the one of a vapor compression cooler working with HFC134a.
\end{abstract}

\section{INTRODUCTION}

Caloric refrigeration is a novel emerging class of cooling techniques based on solid-state materials [1]. It is founded upon caloric effect, detected in ferro-caloric materials [2] manifesting itself as a temperature change as a consequence of a variation of an applied driving field in an adiabatic process. Dually, the same field variation happening in isothermal process determines an entropy variation, as described respectively as follows:

$\Delta s=\int_{Y_{0}}^{Y_{1}}\left(\frac{\partial X}{\partial T}\right)_{Y} d Y$

$\Delta T_{a d}=-\int_{Y_{0}}^{Y_{1}} \frac{T}{C}\left(\frac{\partial X}{\partial T}\right)_{Y} d Y$

The nature of the driving field particularizes the caloric effect [3]. Magnetic fields applied to a magnetocaloric materials give rise to magnetocaloric effect (MCE)[4] where $Y=H$ and $X=M$, electric fields to electrocaloric effect (ECE) [5] where $Y=E$ and $X=P$, mechanical stress to elastocaloric effect (eCE) [6], where $Y=\sigma$ and $X=\varepsilon$, pressure field to barocaloric effect (BCE) [7] where $Y=-p$ and $X=V$.

Caloric effects are exploited in a Brayton based thermodynamical cycle [8] (Figure 1 (a)) applied to an Active Caloric Regenerator (ACR), made of the solid-state caloric refrigerant and acting both as refrigerant and regenerative medium to recover heat fluxes. ACR counts four processes, reported in Figure 1 (b), executed sequentially and cyclically, applied to a regenerator. The latter is placed between a cold and a hot reservoir (CHEX and HHEX), subjected to a variable flied and free to be crossed by a thermo-vector fluid. The four processes are:

a) adiabatic field increasing;

b) fluid flows from cold to hot side;

c) adiabatic field decreasing;

d) fluid flows from hot to cold side.

During the field increasing process (A), the external field applied to the caloric material, is increased until reaching the maximum value $\left(F_{1}\right)$ while the fluid is not flowing, causing the increasing of the material temperature, due to caloric effect. In the second stage (B), the field remains constant and the cold fluid crosses the ACR from the cold to the hot side, thus cooling the regenerator and rejecting heat in the external environment through the hot heat exchanger. When in the third stage (C) the field is reduced until reaching the minimum value $\left(\mathrm{F}_{0}\right)$, while the fluid hasn't any motion, the regenerator sees another decrement in its temperature, thanks to caloric effect. As a final stage (D), while the field is absent, the fluid flows across the regenerator from the hot to cold side, cooling itself and then reaching the cold heat exchanger, where it absorbs heat from the latter, producing a cooling load. The strongpoint of caloric refrigeration is the employment of solid state materials that do not provide a direct contribution in global warming [9], since they do not disperse in the atmosphere. Only an indirect impact is registered when they are employed as refrigerants in cooling systems. On the contrary, vapor compression, the main actual cooling technique, employs fluid-state refrigerants which carry on both direct and indirect [10-11] contribution in global warming. 


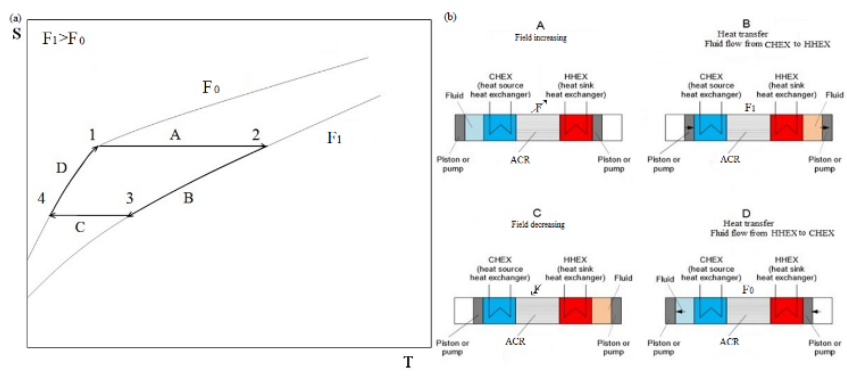

Figure 1. (a) Brayton cycle; (b) ACR cycle

More than $20 \%$ of energy consumption is due to vapor compression [12], since human activities increase continuously despite of the recent prescription of national laws coming out from the indication and the measures given by Montreal [13], Kyoto Protocol [14] and, more recently, Kigali amendment [15] to the Montreal protocol. Therefore, actually most of the refrigerant fluids working in vapour compression plants are environmentally harmful. Near all the efforts done [16-19] in the identification of new refrigerant fluids, environmentally friendly, to be employed in VCP, in the last decades the interest of scientific community has oriented itself in studying and developing new refrigeration technologies of low impact in our ecosystem [20-21]. As a matter of fact, the evaluation of the environmental impact is a deeply felt issue [22-24]. The main parameter to evaluate global warming impact and carbon-dioxide emissions coming out from a cooler is the Total Environmental Warming Impact (TEWI) index, which accounts both the direct and indirect contributions produced. In this paper a $\triangle$ TEWI analysis is presented, comparing numerically the environmental impact of a caloric refrigerator, operating with different caloric materials, with the one of a vapor compression cooler working with HFC134a. As a matter of fact, numerical modeling ensures good predictions of energetic results [25-29]. By means of a two-dimensional mathematical model the analysis is performed with the most performing magnetocaloric, electrocaloric, elastocaloric and barocaloric materials in order to provide a general framework of caloric cooling technique.

\section{2-D MODEL}

The model employed for the presented investigation is a two-dimensional numerical model of an ACR operating at room temperature. The regenerator has a rectangular shape $(20 \times 45 \mathrm{~mm})$. The area is filled with 54 parallel plates of caloric material; every plate has a thickness of $0.25 \mathrm{~mm}$. The solid-state material occupies globally $60 \%$ of the total area of the regenerator. The interstitial spaces stacked by each two plates are channels where an auxiliary fluid flows with the purpose of heat transferring. Different sets of equations, describing the ACR cycle in the four phases, are applied to the model. The equations that rule the regenerative fluid flow processes, in both directions, are: the Navier-Stokes for the fluid flow and the energy equations for both the fluid and the solid particles. With the assumptions that the fluid is incompressible, laminar and the viscous dissipation neglected, the equations are:

$$
\left\{\begin{array}{c}
\frac{\partial u}{\partial x}+\frac{\partial v}{\partial y}=0 \\
\frac{\partial u}{\partial t}+u \frac{\partial u}{\partial x}+v \frac{\partial u}{\partial y}=-\frac{1}{\rho_{f}} \frac{\partial p}{\partial x}+v\left(\frac{\partial^{2} u}{\partial x^{2}}+\frac{\partial^{2} u}{\partial y^{2}}\right) \\
\frac{\partial v}{\partial t}+u \frac{\partial v}{\partial x}+v \frac{\partial v}{\partial y}=-\frac{1}{\rho_{f}} \frac{\partial p}{\partial y}+v\left(\frac{\partial^{2} v}{\partial x^{2}}+\frac{\partial^{2} v}{\partial y^{2}}\right) \\
\frac{\partial T_{f}}{\partial t}+u \frac{\partial T_{f}}{\partial x}+v \frac{\partial T_{f}}{\partial y}=\frac{k_{f}}{\rho_{f} C_{f p}}\left(\frac{\partial^{2} T_{f}}{\partial x^{2}}+\frac{\partial^{2} T_{f}}{\partial y^{2}}\right) \\
\frac{\partial T_{s}}{\partial t}=\frac{k_{s}}{\rho_{s} C_{s p}}\left(\frac{\partial^{2} T_{s}}{\partial x^{2}}+\frac{\partial^{2} T_{s}}{\partial y^{2}}\right)
\end{array}\right.
$$

The equations that model the field increasing and decreasing processes are:

$$
\left\{\begin{array}{c}
\rho_{f} C_{f p} \frac{\partial T_{f}}{\partial t}=k_{f}\left(\frac{\partial^{2} T_{f}}{\partial x^{2}}+\frac{\partial^{2} T_{f}}{\partial y^{2}}\right) \\
\rho_{s} C_{s p} \frac{\partial T_{s}}{\partial t}=k_{s}\left(\frac{\partial^{2} T_{s}}{\partial x^{2}}+\frac{\partial^{2} T_{s}}{\partial y^{2}}\right)+Q
\end{array}\right.
$$

They must include caloric effect which increases or decreases the temperature of the solid by the variation of the external driving field applied to the regenerator. Hence, the adiabatic temperature variation $\Delta \mathrm{T}_{\mathrm{ad}}$ is converted into a heat source Q as:

$Q=Q\left(\right.$ field,$\left.T_{S}\right)=\frac{\rho_{S} C_{S p}\left(\text { field }, T_{S}\right) \Delta T_{a d}\left(\text { field }, T_{S}\right)}{\Delta t}$

Q has the dimensions of a power density and it is included in the solid energy equation, only for field increasing and decreasing phases [30]. It is positive during the former, negative during the latter. $\Delta \mathrm{t}$ is the period of the field increasing/decreasing process. The coupled equations that govern the ACR cycle, imposed on this model, are solved using Finite Element Method. The ACR cycle is modeled as four sequential steps. The same time step $\Delta \mathrm{t}$ has been chosen for the resolution during all the four periods of the cycle. The cycle is repeated several times with constant operating frequency until the regenerator reaches steady state operation.

The strongpoint of the model is the possibility to model every particular caloric material and, therefore, to consider all the four-principal caloric effects. As a matter of fact, in this paper is reported an investigation which treats MCE, ECE, eCE and BCE materials. Therefore, the model, time after time, assumes the role of Active Magnetic Regenerator (AMR), Active Electrocaloric Regenerator (AER), Active elastocaloric Regenerator (AeR) and Active Barocaloric Regenerator (ABR). The model has been validated experimentally with a rotary magnetic refrigerator developed at University of Salerno [31-36].

\section{SOLID-STATE REFRIGERANTS}

In the general framework of caloric materials possible candidates to solid state refrigeration, in this paper, four subgroups have been considered: magnetocaloric, electrocaloric, elastocaloric and barocaloric materials with the common characteristic to exhibit a pronounced caloric effect in room temperature range when the field reaches not so elevated maximum intensities. 


\subsection{Magnetocaloric materials}

In the former subgroup, gadolinium (Gd) has for sure to be taken in consideration since, starting from the beginning of the diffusion of magnetic refrigeration, it has been always considered the benchmark material of such technique. Belonging to the lanthanide group, gadolinium is a rare-earth element which exhibits a second order paramagnetic to ferromagnetic transition at its Curie temperature $\left(\mathrm{T}_{\text {Curie }}=294 \mathrm{~K}\right)$ [37]. Other interesting materials are $\mathrm{Gd}_{5}\left(\mathrm{Si}_{1-\mathrm{x}} \mathrm{Ge}_{\mathrm{x}}\right)_{4}$ compounds (where $0<\mathrm{x}<0.5$ ), they are alloys of gadolinium, silicon and germanium. In particular, $\mathrm{Gd}_{5} \mathrm{Si}_{2} \mathrm{Ge}_{2}$ [38] exhibits the larger MCE among them, presenting two different phase transitions: at $276 \mathrm{~K}$ where the highest peak is located, and at $299 \mathrm{~K}$ where, according to it, the material orders paramagnetically. Also, the rare-earth transitionmetals $\mathrm{La}\left(\mathrm{Fe}_{\mathrm{x}} \mathrm{Si}_{1-\mathrm{x}}\right)_{13}$ have been considered because of the large MCE exhibiting around room temperature. The main advantages of employing $\mathrm{La}\left(\mathrm{Fe}_{\mathrm{x}} \mathrm{Si}_{1-\mathrm{x}}\right)_{13}$ alloys are the cheapness, readily availability and easiness of preparing. They present a first-order itinerant electron metamagnetic transition which produces a giant magnetocaloric effect. Among them $\mathrm{LaFe}_{11.384} \mathrm{Mn}_{0.356} \mathrm{Si}_{1.26} \mathrm{H}_{1.52}$ [39] and $\mathrm{LaFe}_{11.05} \mathrm{Co}_{0.94} \mathrm{Si}_{1.10} \quad$ [40] have been selected. Both compounds have a first order transition at 290 and $287 \mathrm{~K}$, respectively. Table 1 summarizes the characteristics of the presented magnetic materials in the room temperature range. The $\Delta \mathrm{T}_{\mathrm{ad}}$ reported is the peak value with a magnetic field variation $\Delta \mathrm{H}$ in $[0 ; 1.5] \mathrm{T}$.

Table 1. Features of the selected magnetocaloric materials

\begin{tabular}{ccccc}
\hline Material & $\begin{array}{c}\mathbf{T}_{\text {peak }} \\
{[\mathbf{K}]}\end{array}$ & $\begin{array}{c}\Delta \mathbf{T}_{\text {ad }} \\
{[\mathbf{K}]}\end{array}$ & $\begin{array}{c}\mathbf{\rho} \\
{\left[\mathbf{k g} / \mathbf{m}^{3}\right]}\end{array}$ & $\begin{array}{c}\mathbf{k} \\
{[\mathbf{W} / \mathbf{m K}]}\end{array}$ \\
\hline $\mathrm{Gd}$ & 294 & 6 & 7900 & 10.9 \\
\hline $\mathrm{Gd}_{5}\left(\mathrm{Si}_{\mathrm{x}} \mathrm{Ge}_{1-\mathrm{x}}\right)_{4}$ & 276 & 14 & 7205 & 5.8 \\
\hline $\mathrm{LaFe}_{11.384} \mathrm{Mn}_{0.356} \mathrm{Si}_{1.26} \mathrm{H}_{1.52}$ & 290 & 5 & 7100 & 9 \\
\hline $\mathrm{LaFe}_{11.05} \mathrm{Co}_{0.94} \mathrm{Si}_{1.10}$ & 287 & 5.5 & 7290 & 8.9 \\
\hline
\end{tabular}

\subsection{Electrocaloric materials}

The subgroup of materials selected in such study for electrocaloric refrigeration embraces both bulk (singlecrystals and ceramics) and films (polymers and ceramics) materials. $\quad \mathrm{P}(\mathrm{VDF}-\mathrm{TrFE}-\mathrm{CFE}) / \mathrm{BSTs}$ polymer nanocomposities [41] have been selected, for their high ECE, since they are made up of a polymer matrix of $\mathrm{P}(\mathrm{VDF}-\mathrm{TrFE}-$ CFE) $62.3 / 29.9 / 7.8 \mathrm{~mol} \%$ doped with $\left(\mathrm{Ba}_{\mathrm{x}} \mathrm{Sr}_{1-\mathrm{x}} \mathrm{TiO}_{3}\right)$, to reduce the ferroelectric domain size and the energy bandgap to phase transition. Thus, doping with $\mathrm{Ba}_{0.67} \mathrm{Sr}_{0.33} \mathrm{TiO}_{3}$ (BST67), $\mathrm{Ba}_{0.71} \mathrm{Sr}_{0.29} \mathrm{TiO}_{3}$ (BST71), $\mathrm{Ba}_{0.74} \mathrm{Sr}_{0.26} \mathrm{TiO}_{3}$ (BST74), $\mathrm{Ba}_{0.77} \mathrm{Sr}_{0.23} \mathrm{TiO}_{3}$ (BST77) increases the intensity of the electrical field induction which carries to enhanced ECE with quite low electric field applied. Another material chosen is 0.93PMN-0.07PT thin film [42] because of its giant ECE at $300 \mathrm{~K}$. It is made up of the $\mathrm{PbMg}_{2 / 3} \mathrm{Nb}_{1 / 3} \mathrm{O}_{3}$ relaxor ceramic, filled with $\mathrm{PbTiO}_{3}(\mathrm{PT})$, to achieve a wide-range of dipolar ordering. PLZT $\mathrm{Pb}_{1-3 \mathrm{x} / 2} \mathrm{La}_{\mathrm{x}} \mathrm{Zr}_{0.85} \mathrm{Ti}_{0.15} \mathrm{O}_{3}$ [43] thick films have been considered: worthy of consideration are the "up-graded" and the "down-graded" antiferroelectric compositions obtained, respectively, by increasing the La content from 8 to $14 \mathrm{~mol} \%$ and vice-versa, to improve many dielectric characteristics. Also, PLZT 11/85/15 in single composition has been tested. Moreover the giant ECE $\left(\Delta \mathrm{T}_{\mathrm{ad}}=45.3 \mathrm{~K}\right.$ at $59.8 \mathrm{MVm}^{-1}$ ) in relaxor ferroelectric $\mathrm{Pb}_{0.8} \mathrm{Ba}_{0.2} \mathrm{ZrO}_{3}$ (PBZ)
[44] thin film fabricated on $\mathrm{Pt}(111) / \mathrm{TiO}_{\mathrm{x}} / \mathrm{SiO}_{2} / \mathrm{Si}$ substrate by a sol-gel method, in which nano-scaled antiferroelectric (AFE) and ferroelectric (FE) phases coexist, at room temperature $(290 \mathrm{~K})$ rather than at its Curie temperature (408 $\mathrm{K})$. Lastly, a $2 \mathrm{~mm}-\mathrm{Pb}_{0.97} \mathrm{La}_{0.02}\left(\mathrm{Zr}_{0.75} \mathrm{Sn}_{0.18} \mathrm{Ti}_{0.07}\right) \mathrm{O}_{3}$ (PLZST) antiferroelectric (AFE) thick film with tetragonal structure deposited on $\mathrm{LaNiO}_{3} / \mathrm{Si}$ (100) substrates via a sol-gel technique [45], has been considered because of its giant ECE shown in the range $5^{\circ} \mathrm{C}$ to $25^{\circ} \mathrm{C}$. In Table 2 all the $\mathrm{EC}$ materials are summarized thus a comparison could be done [46].

Table 2. Features of the selected electrocaloric materials

\begin{tabular}{|c|c|c|c|c|c|}
\hline Material & $\begin{array}{c}\mathbf{T}_{\text {pea }} \\
\mathbf{k} \\
{[\mathbf{K}]}\end{array}$ & $\begin{array}{c}\Delta \mathbf{E} \\
{[\mathbf{M V} /} \\
\mathbf{m}]\end{array}$ & $\begin{array}{c}\Delta \mathbf{T}_{\mathrm{a}} \\
\mathrm{d} \\
{[\mathrm{K}]}\end{array}$ & $\begin{array}{c}\rho \\
{[\mathrm{kg} / \mathrm{m}} \\
3]\end{array}$ & $\begin{array}{c}\mathbf{k} \\
{[\mathbf{W} / \mathbf{m}} \\
\mathbf{K}]\end{array}$ \\
\hline $\begin{array}{l}\text { P(VDF-TrFE- } \\
\text { CFE)/BST67 }\end{array}$ & 311 & 75 & 9.2 & 2060 & 1 \\
\hline $\begin{array}{l}\text { P(VDF-TrFE- } \\
\text { CFE)/BST71 }\end{array}$ & 322 & 75 & 9.4 & 2060 & 1 \\
\hline $\begin{array}{l}\text { P(VDF-TrFE- } \\
\text { CFE)/BST74 }\end{array}$ & 331 & 75 & 9.7 & 2030 & 1 \\
\hline $\begin{array}{l}\text { P(VDF-TrFE- } \\
\text { CFE)/BST77 }\end{array}$ & 337 & 75 & 9.9 & 2060 & 1 \\
\hline $0.93 \mathrm{PMN}-0.07 \mathrm{PT}$ & 298 & 50.9 & 9 & 8300 & 1.4 \\
\hline $0.93 \mathrm{PMN}-0.07 \mathrm{PT}$ & 298 & 72.3 & 13 & 8300 & 1.4 \\
\hline PLTZ upgraded & 1 & 90 & 28 & 7900 & 1.9 \\
\hline PLTZ downgraded & 1 & 90 & 20 & 7900 & 1.9 \\
\hline PLZT11/85/15 & 111 & 90 & 12 & 7900 & 1.9 \\
\hline $\mathrm{Pb}_{0.8} \mathrm{Ba}_{0.2} \mathrm{ZrO}_{3}$ & 290 & 59.8 & 45 & 7700 & 1 \\
\hline $\mathrm{Pb}_{0.8} \mathrm{Ba}_{0.2} \mathrm{ZrO}_{3}$ & 290 & 40.8 & 36 & 7700 & 1 \\
\hline $\mathrm{Pb}_{0.8} \mathrm{Ba}_{0.2} \mathrm{ZrO}_{3}$ & 290 & 21 & 20 & 7700 & 1 \\
\hline $\begin{array}{c}\mathrm{Pb}_{0.97} \mathrm{La}_{0.02} \\
\left(\mathrm{Zr}_{0.75} \mathrm{Sn}_{0.18} \mathrm{Ti}_{0.07}\right) \mathrm{O}_{3}\end{array}$ & 278 & 90 & 54 & 8300 & 1 \\
\hline $\begin{array}{c}\mathrm{Pb}_{0.97} \mathrm{La}_{0.02} \\
\left(\mathrm{Zr}_{0.75} \mathrm{Sn}_{0.18} \mathrm{Ti}_{0.07}\right) \mathrm{O}_{3}\end{array}$ & 278 & 70 & 43 & 8300 & 1 \\
\hline $\begin{array}{c}\mathrm{Pb}_{0.97} \mathrm{La}_{0.02} \\
\left(\mathrm{Zr}_{0.75} \mathrm{Sn}_{0.18} \mathrm{Ti}_{0.07}\right) \mathrm{O}_{3}\end{array}$ & 278 & 60 & 33 & 8300 & 1 \\
\hline
\end{tabular}

\subsection{Elastocaloric materials}

Since giant elastocaloric effect was reported at room temperature for a $\mathrm{Cu}-\mathrm{Zn}-\mathrm{Al}$ single crystal and for $\mathrm{Ni}-\mathrm{Ti}$ polycrystals, among elastocaloric materials two candidates have been considered:

a) $\mathrm{Cu}_{68.13} \mathrm{Zn}_{15.74} \mathrm{Al}_{16.13}$ [47] which, for a stress varying in $[0 ; 140] \mathrm{MPa}$ range, exhibits constant values of $\Delta \mathrm{s}(21$ $\mathrm{J} / \mathrm{kgK})$ and $\Delta \mathrm{T}_{\mathrm{ad}}(16 \mathrm{~K})$ at room temperature.

b) $\mathrm{Ni}-\mathrm{Ti}[48]$ stressed under $\Delta \sigma=900 \mathrm{MPa}$, which shows a maximum $\Delta \mathrm{T}_{\text {ad }}$ of about $25 \mathrm{~K}$ at $350 \mathrm{~K}$.

Table 3 lists in detail the features of the above-mentioned materials.

Table 3. Features of the selected elastocaloric materials

\begin{tabular}{cccccc}
\hline Material & $\begin{array}{c}\mathbf{T}_{\text {peak }} \\
{[\mathbf{K}]}\end{array}$ & $\begin{array}{c}\Delta \boldsymbol{\sigma} \\
{[\mathbf{M P a}]}\end{array}$ & $\begin{array}{c}\Delta \mathbf{T}_{\text {ad }} \\
{[\mathbf{K}]}\end{array}$ & $\begin{array}{c}\mathbf{\rho} \\
{\left[\mathbf{k g} / \mathbf{m}^{3}\right]}\end{array}$ & $\begin{array}{c}\mathbf{k} \\
{[\mathbf{W} / \mathbf{m K}]}\end{array}$ \\
\hline $\mathrm{Cu}_{68.13} \mathrm{Zn}_{15.74} \mathrm{Al}_{16.13}$ & - & 140 & 16 & 7700 & 179 \\
\hline $\mathrm{NiTi}$ & 350 & 900 & 26 & 6450 & 15 \\
\hline
\end{tabular}

\subsection{Barocaloric materials}

In the number of barocaloric candidates for room temperature refrigeration, an interesting comparison has been done. As a matter of fact, the investigation has focused upon 
two distinct materials: the $\left(\mathrm{NH}_{4}\right)_{2} \mathrm{MoO}_{2} \mathrm{~F}_{4}$ oxyfluorides [49], direct $\mathrm{BCE}$ material, whose $\mathrm{T}_{\text {peak }}$ is about located around 272 $\mathrm{K}$ considered for three different pressure fields applied; the hexagonal $\mathrm{Ni}_{2} \mathrm{In}$-type $\mathrm{MnCoGe}_{0.99} \mathrm{In}_{0.01}$ [50] exhibiting an inverse barocaloric effect due to a pressure-driven orthorhombic-hexagonal magneto structural transition. The transition for $\mathrm{MnCoGe}_{0.99} \mathrm{In}_{0.01}$ occurs around $298 \mathrm{~K}$ with a $\Delta \mathrm{T}_{\text {ad }}$ of $-18.3 \mathrm{~K}$. Table 4 contains details about the two barocaloric materials.

Table 4. Features of the selected barocaloric materials

\begin{tabular}{cccccc}
\hline Material & $\begin{array}{c}\mathbf{T}_{\text {peak }} \\
{[\mathbf{K}]}\end{array}$ & $\begin{array}{c}\Delta \mathbf{p} \\
{[\mathbf{M P a}]}\end{array}$ & $\begin{array}{c}\Delta \mathbf{T}_{\text {ad }} \\
{[\mathbf{K}]}\end{array}$ & $\begin{array}{c}\boldsymbol{\rho} \\
{\left[\mathbf{k g} / \mathbf{m}^{3}\right]}\end{array}$ & $\begin{array}{c}\mathbf{k} \\
{[\mathbf{W} / \mathbf{m K}]}\end{array}$ \\
\hline$\left(\mathrm{NH}_{4}\right)_{2} \mathrm{MoO}_{2} \mathrm{~F}_{4}$ & 272 & 900 & 18 & 2200 & 1 \\
\hline$\left(\mathrm{NH}_{4}\right)_{2} \mathrm{MoO}_{2} \mathrm{~F}_{4}$ & 272 & 700 & 15 & 2200 & 1 \\
\hline$\left(\mathrm{NH}_{4}\right)_{2} \mathrm{MoO}_{2} \mathrm{~F}_{4}$ & 272 & 500 & 12 & 2200 & 1 \\
\hline $\mathrm{MnCoGe}_{0.99} \mathrm{In}_{0.01}$ & 298 & 300 & -18.3 & 7900 & 65 \\
\hline
\end{tabular}

\section{THE TEWI CONCEPT}

GWP is the acronym of global warming potential and it is an index employed for quantifying the impact of greenhouse gases on global warming. It counts the mass of $\mathrm{CO}_{2}$ that would result in the same net impact on global warming as the release of a single unit $(\mathrm{kg})$ of the atmospheric component in question. A vapor compression plants is equipped of both a direct and an indirect contribution to global warming. Direct contribution depends on the GWP of refrigerant fluids employed and on the fraction of refrigerant charge released in the atmosphere. The indirect contribution is due to the energy-related contribution. In detail, a vapor compression (VC) system requires electrical energy, coming from a power plant that typically burns a fossil fuel, issuing $\mathrm{CO}_{2}$ to the atmosphere. Therefore, the indirect contribution in global warming is a strong function the Coefficient of Performance (COP) of the VC system, of the power plant efficiency and of the fuel used in the conversion plant that affects the emissions per unit energy converted. The Total Equivalent Warming Impact (TEWI) index accounts both contributions to global warming of the refrigeration system. The concept of TEWI was developed to combine the effect of direct refrigerant emission with the energy consumption and to the related combustion of fossil fuels for the electric energy production. The TEWI is calculated as:

$$
\begin{aligned}
& T E W I=\mathrm{CO}_{2, \text { dir }}+\mathrm{CO}_{2, \text { indir }}\left[\mathrm{kg} \mathrm{CO}_{2}\right] \\
& \mathrm{CO}_{2, \text { dir }}=R C\left[P_{L}+\left(\frac{1-P_{R}}{V}\right)\right] V \cdot G W P \\
& \mathrm{CO}_{2, \text { indir }}=\alpha \cdot \frac{\dot{Q}_{\text {ref }}}{C O P} \cdot \mathrm{H} \cdot \mathrm{V}
\end{aligned}
$$

The direct global warming effect of refrigerant fluids, stemming from the absorption they produce of long-wave radiations, depends on their GWP and on the fraction of refrigerant charge released in the atmosphere [51]. The last is mainly due to leakage during the operational plant life time $\left(\mathrm{P}_{\mathrm{L}}\right)$ and to the residual amounts which, according to the current state of technology, are not recyclable and thus are released to the atmosphere when taking the plant out of operation $\left(1-\mathrm{P}_{\mathrm{R}}\right)$. In the simulation $\mathrm{P}_{\mathrm{L}}$ is assumed as $5 \%$, whereas $P_{R}$ has not been considered. The literature provides some indicative, average levels of $\mathrm{CO}_{2}$ release per $\mathrm{kWh}$ of electrical energy for various countries. For Italy, the value is $0.6 \mathrm{~kg} \mathrm{CO}_{2} / \mathrm{kWh}$. The annual power consumption assumed is $290 \mathrm{kWh}$ per year that corresponds to a commercial medium size wine cooler. R134a is an HFC with zero ODP and a GWP of 1430 .

\section{NUMERICAL SIMULATIONS}

The investigation has been performed simulating several ACR cycles for the caloric materials listed and described in section 3 . The ranges where external applied fields vary are related to the particular caloric material under test and they are explicated in Tables 1-4; whereas the thermodynamical working conditions under which the simulations have been done are common for all the four classes of materials. Fixed are active caloric cycle frequency $(1.25 \mathrm{~Hz})$, cold and hot heat exchanger temperatures $\left(T_{C}=287 \mathrm{~K}, T_{H}=295 \mathrm{~K}\right)$ while fluid flow rate was varied in the range $0.034 \div 0.057 \mathrm{~kg}^{*} \mathrm{~s}^{-1}$.

\section{RESULTS}

The results of the presented investigation are reported in terms of Coefficient of Performance and relative percentage $\triangle T E W I$ index. In detail, COP and the relative percentage $\triangle$ TEWI have been considered as:

$$
\begin{aligned}
& C O P=\frac{\dot{Q}_{r e f}}{\dot{Q}_{H}-\dot{Q}_{r e f}+\dot{W}_{p}} \\
& \triangle T E W I=\frac{\left(T E W I_{A C R}-T E W I_{V C}\right)}{T E W I_{V C}}
\end{aligned}
$$

The TEWI direct contribution of an ACR cycle is zero because the refrigerant is solid-state and it has no GWP. Direct contribution of the vapor compression plant accounts about $10 \%$ of the whole value. COP of the plant is the parameter that mostly affects the TEWI indirect contribution.

Figure 2 shows COP as a function of fluid flow rate for the (a) magnetocaloric, (b)(c) electrocaloric, (d) elastocaloric, (e) barocaloric materials tested. Every class contains its best materials: as a matter of fact, among magnetocaloric materials $\mathrm{GdSi}_{2} \mathrm{Ge}_{2}$ stands out, whose COPs under $\Delta \mathrm{H}=1.5 \mathrm{~T}$ are comparable with the electrocaloric $\mathrm{Pb}_{0.97} \mathrm{La}_{0.02}$ $\left(\mathrm{Zr}_{0.75} \mathrm{Sn}_{0.18} \mathrm{Ti}_{0.07}\right) \mathrm{O}_{3}$, the elastocaloric $\mathrm{Cu}_{68.13} \mathrm{Zn}_{15.74} \mathrm{Al}_{16.13}$ and the barocaloric $\left(\mathrm{NH}_{4}\right)_{2} \mathrm{MoO}_{2} \mathrm{~F}_{4}$, under external field changes of $\Delta \mathrm{E}=90 \mathrm{MV} / \mathrm{m}, \Delta \sigma=140 \mathrm{MPa}$ and $\Delta \mathrm{p}=900 \mathrm{MPa}$, respectively. Best COPs are proper of the electrocaloric $\mathrm{Pb}_{0.97} \mathrm{La}_{0.02}\left(\mathrm{Zr}_{0.75} \mathrm{Sn}_{0.18} \mathrm{Ti}_{0.07}\right) \mathrm{O}_{3}$, with a maximum of 16.8 under $\Delta \mathrm{E}=90 \mathrm{MV} / \mathrm{m}$.

Figure 3 exhibits the relative percentage $\triangle T E W I$ indexes for the (a) magnetocaloric, (b)(c) electrocaloric, (d) elastocaloric, (e) barocaloric materials tested and evaluated with respect to a vapor compression plant working under the same operating conditions. The VCP used in the simulation is a commercial, small size, wine cooler working with R134 with a semi-hermetic compressor, air cooled condenser, forced air circulating evaporator.

Figure 3 clearly shows that the ACR cycle working with these materials has almost always a lower greenhouse effect with respect to a VCP. In the group of magnetocaloric materials the lowest $\triangle \mathrm{TEWI}$ belongs to $\mathrm{GdSi}_{2} \mathrm{Ge}_{2}$ with values belonging to $[-60 ;-70] \%$. Among electrocaloric materials, 
with $\mathrm{Pb}_{0.97} \mathrm{La}_{0.02}\left(\mathrm{Zr}_{0.75} \mathrm{Sn}_{0.18} \mathrm{Ti}_{0.07}\right) \mathrm{O}_{3} \Delta \mathrm{TEWI}$ varies between a minimum of $-50 \%$ to a maximum of $-82 \%$. The elastocaloric $\mathrm{Cu}_{68.13} \mathrm{Zn}_{15.74} \mathrm{Al}_{16.13}$ ensures an environmental impact from $-49 \%$ to $-72 \%$ smaller than the VCP one. Also the barocaloric $\left(\mathrm{NH}_{4}\right)_{2} \mathrm{MoO}_{2} \mathrm{~F}_{4}$ shows a promising behavior with a $\triangle$ TEWI around $-70 \%$.

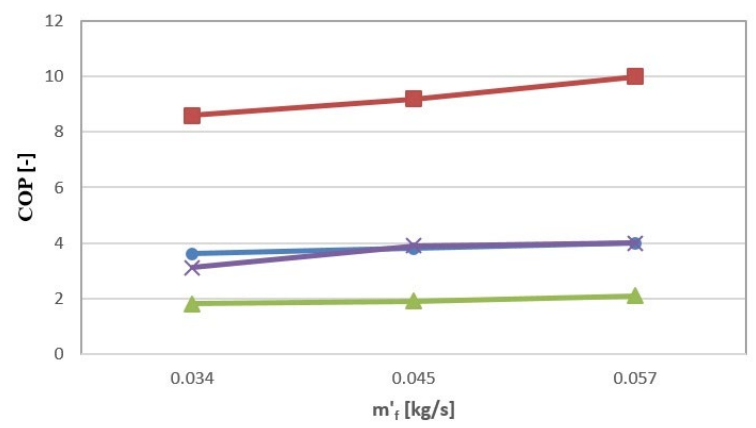

(a) $\rightarrow$ Gd $\quad=G d 5(S i 2 G e 2)$

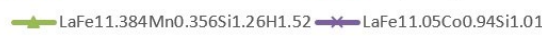
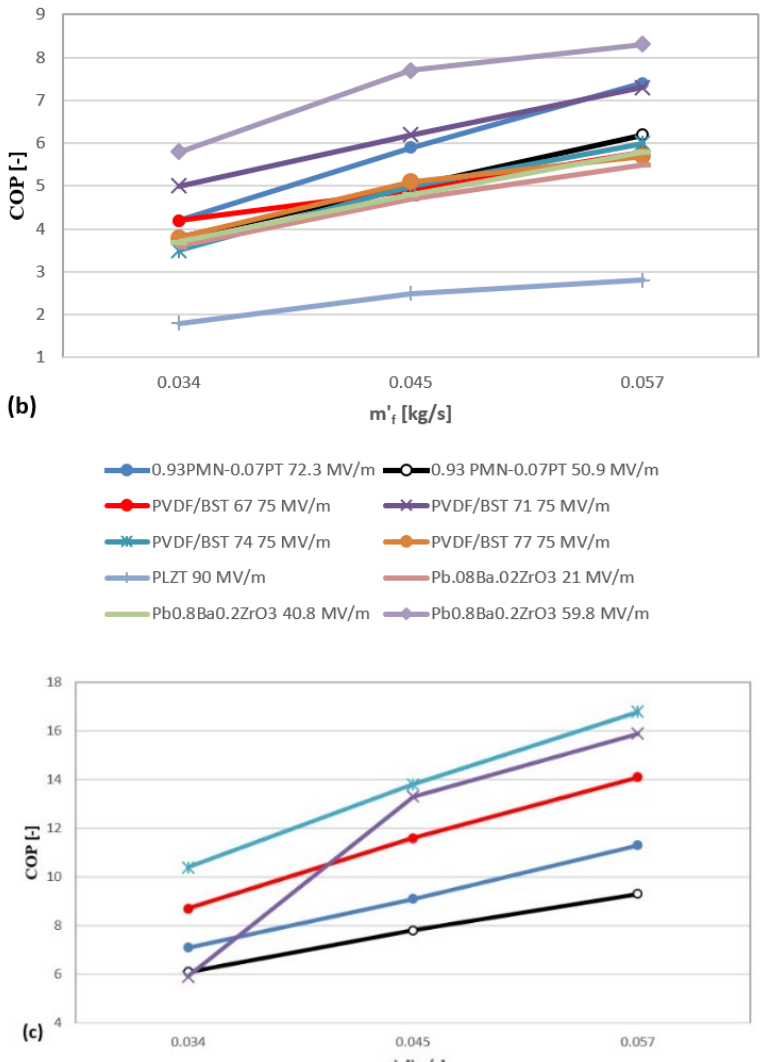

mi, [kg/s]

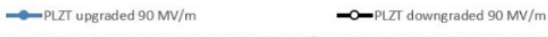

—.

-Pb0.8L L 0.02 (Zro.755no.18Tio.07) $0390 \mathrm{MV} / \mathrm{m}$

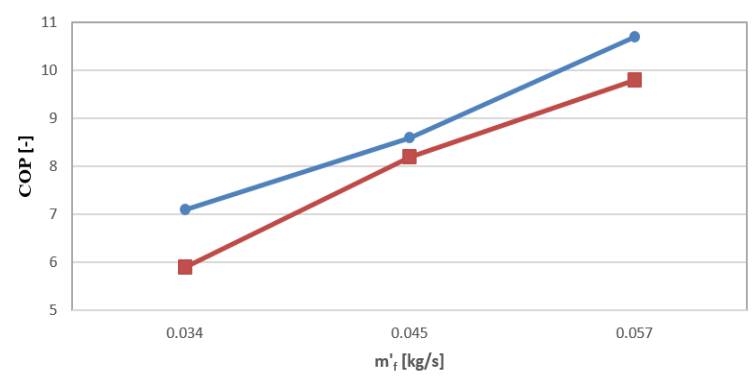

(d)

$\rightarrow$ Cu68.13Zn15.74Al16.13 $\Delta 0=140 \mathrm{MPa} \quad \rightarrow$ NiTi $\Delta 0=900 \mathrm{MP}$

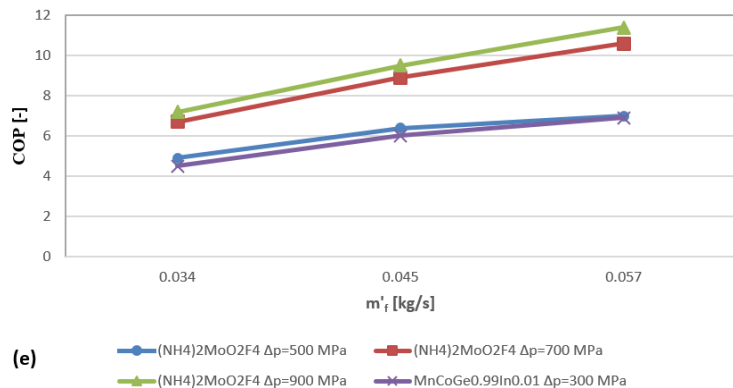

Figure 2. COP vs fluid flow rate for: (a) magnetocaloric materials under a magnetic field variation $\Delta \mathrm{H}$ in $[0 ; 1.5] \mathrm{T}$; (b) the first and (c) the second group of electrocaloric materials;

(d) elastocaloric materials; (e) barocaloric materials

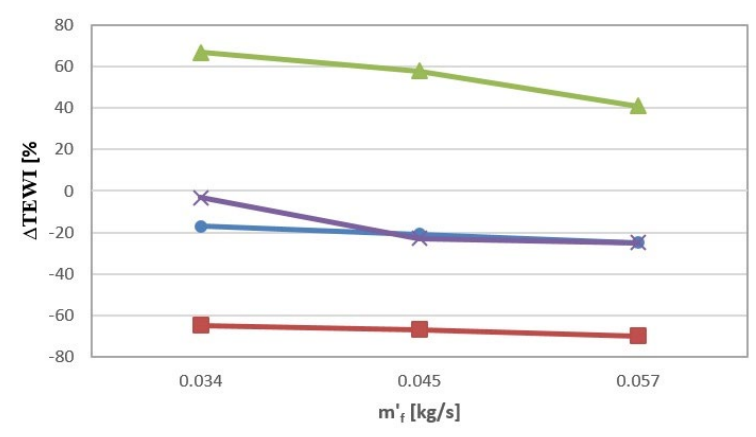

(a)

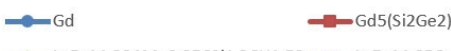

LLaFe11.384Mn0.356Si1.26H1.52 L LaFe11.05Co0.94Si1.01

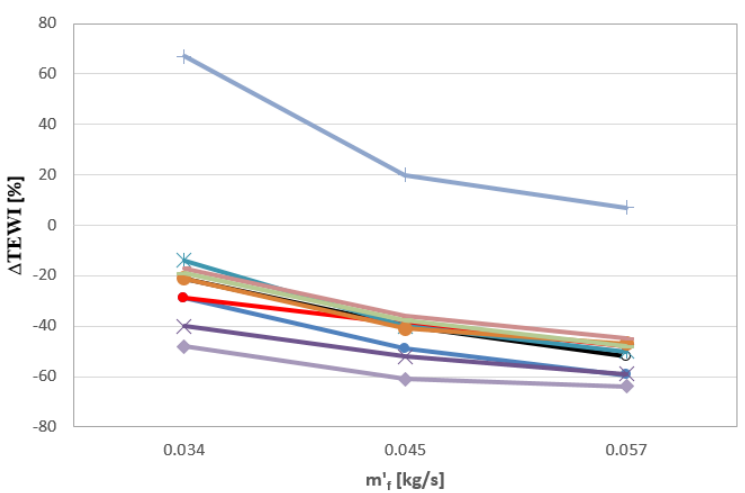

(b) $\quad \longrightarrow 0.93$ PMN -0.07 PT $72.3 \mathrm{MV} / \mathrm{m} \longrightarrow 0.03$ PMN-0.07PT $50.9 \mathrm{MV} / \mathrm{m}$

—PVDF/BST $6775 \mathrm{MV} / \mathrm{m} \longrightarrow$ PVDF/BST $7175 \mathrm{MV} / \mathrm{m}$

\#PVDF/BST $7475 \mathrm{MV} / \mathrm{m}$-PVDF/BST $7775 \mathrm{MV} / \mathrm{m}$

—PLZT $90 \mathrm{MV} / \mathrm{m}$ —Pb.08Ba.02Zro3 $21 \mathrm{MV} / \mathrm{m}$

-Pb0.8Ba0.2ZrO3 40.8 MV/m —Pb0.8Ba0.2Zro3 59.8 MV/m

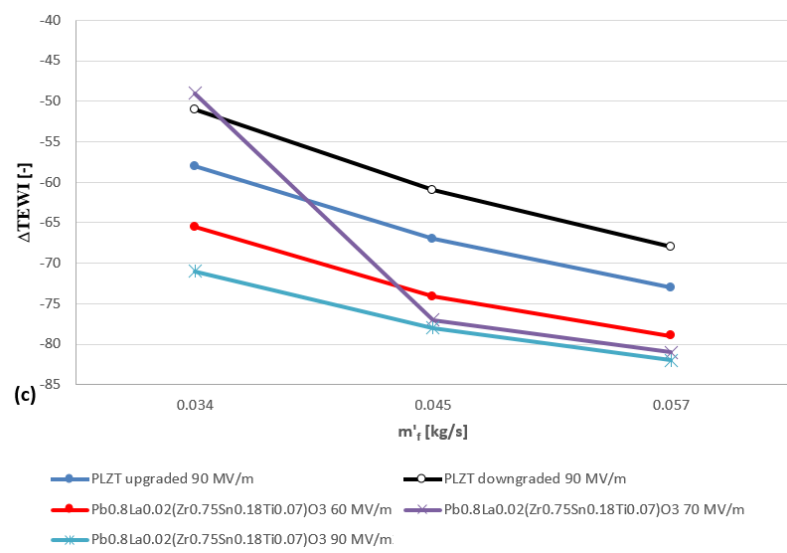




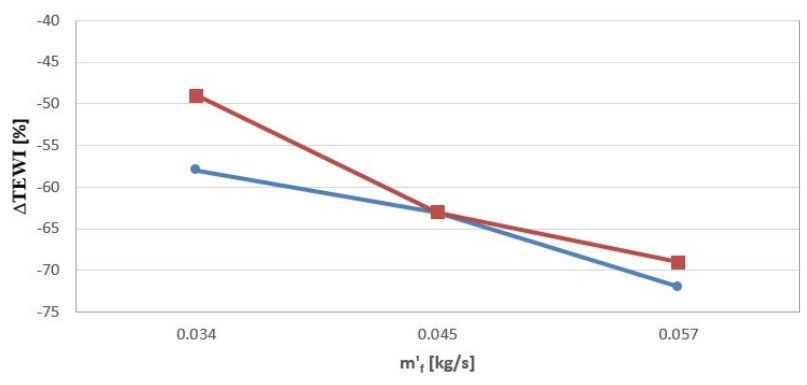

(d)

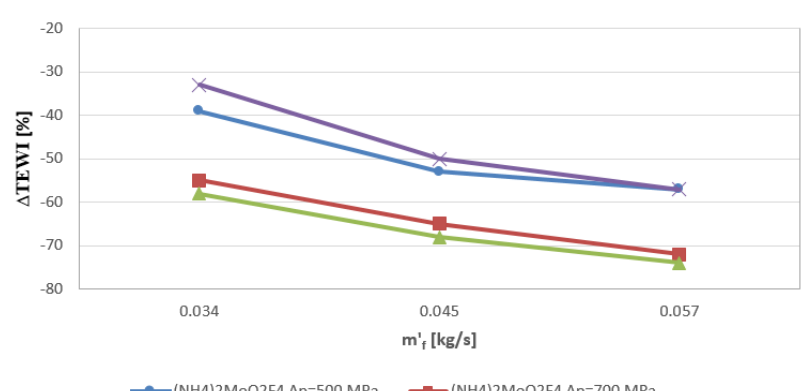

(e) $\quad \longrightarrow$ (NH4)2Mo02F4 $\triangle \mathrm{p}=500 \mathrm{MPa} \quad \longrightarrow$ (NH4)2Mo02F4 $\triangle \mathrm{p}=700 \mathrm{MPa}$

L-(NH4)2Mo02F4 $\triangle \mathrm{p}=900 \mathrm{MPa} \quad$ MnCoGe0.991n0.01 $\Delta \mathrm{p}=300 \mathrm{MPa}$

Figure 3. $\triangle \mathrm{TEWI}$ vs fluid flow rate for: (a) magnetocaloric materials under a magnetic field variation $\Delta \mathrm{H}$ in $[0 ; 1.5] \mathrm{T}$; (b) the first and (c) the second group of electrocaloric materials;

(d) elastocaloric materials; (e) barocaloric materials, compared with a VC plant in the same working conditions

\section{CONCLUSIONS}

In this paper, the environmental impact of an active solidstate refrigerator has been evaluated by means of a numerical TEWI analysis carried out through a 2D model. A number of caloric materials exhibiting one of the four main caloric effect (MCE, ECE, eCE, BE), has been tested as refrigerant of the modeled solid-state refrigerator to provide a general framework of the technique. The refrigerator has been tested working in the same operative conditions of a commercial medium size wine cooler based on vapor compression and employing R134a. The results, presented in terms of COP and $\triangle T E W I$, demonstrates, for almost all the materials tested, that solid-state refrigeration is a cooling technique which ensures a reduction of the environmental impact belonging to $[-30 ;-80] \%$ with respect to a commercial VC wine cooler employing R134a. Caloric refrigeration seems to be a promising cooling technique which hopefully in a not so long future can be commercialized. First, however, some critical points that currently constitute the bottleneck of the technique must be resolved, like the possibility of employing the refrigerator in wider $\mathrm{T}_{\mathrm{C}} \div \mathrm{T}_{\mathrm{H}}$ ranges, that actually it is limited due to the material temperature ranges where caloric effect is pronounced.

\section{REFERENCES}

[1] Kitanovski A, Plaznik U, Tomc U, Poredoš A. (2015). Present and future caloric refrigeration and heat-pump technologies. International Journal of Refrigeration 57: 288-298. https://doi.org/10.1016/j.ijrefrig.2015.06.008

[2] Planes A, Stern-Taulats E, Castán T, Vives E, Mañosa
L, Saxena A. (2015). Caloric and multicaloric effects in shape memory alloys. Materials Today: Proceedings 2: S477-S484. https://doi.org/10.1016/j.matpr.2015.07.332

[3] Aprea C, Greco A, Maiorino A., Masselli C. (2018). A comparison between different materials with mechanocaloric effect. International Journal of Heat and Technology 36(3): 801-807. https://doi.org/10.18280/ijht.360304

[4] Pecharsky VK, Gschneidner Jr KA. (1999) Magnetocaloric effect and magnetic refrigeration. J. of Magn. and Magn. Mat. 200(1-3): 44-56. https://doi.org/10.1016/S0304-8853(99)00397-2

[5] Ju YS. (2010). Solid-state refrigeration based on the electrocaloric effect for electronics cooling. Journal of Electronic Packaging 132(4): 041004. https://doi.org/10.1115/1.4002896

[6] Tušek J, Engelbrecht K, Millán-Solsona R, Mañosa L, Vives E, Mikkelsen LP, Pryds N. (2015). The elastocaloric effect: a way to cool efficiently. Adv. En. Mat. 5(13). https://doi.org/10.1002/aenm.201500361

[7] Strässle T, Furrer A, Dönni A, Komatsubara T. (2002). Barocaloric effect: The use of pressure for magnetic cooling in $\mathrm{Ce}_{3} \mathrm{Pd}_{20} \mathrm{Ge}_{6}$. Journal of Applied Physics 91(10): 8543-8545. https://doi.org/10.1063/1.1456450

[8] Rowe AM, Barclay JA. (2003). Ideal magnetocaloric effect for active magnetic regenerators. J. of Appl. Physics 93(3): 1672-1676. https://doi.org/10.1063/1.1536016

[9] Aprea C, Greco A, Maiorino A, Masselli C. (2017). Electrocaloric refrigeration: an innovative, emerging, eco-friendly refrigeration technique. IOP Conf. Series: Journal of Physics: Conf. Series 796012019. https://doi.org/10.1088/1742-6596/796/1/012019

[10] Mota-Babiloni A, Navarro-Esbrí J, Barragán-Cervera Á, Molés F, Peris B. (2015). Analysis based on EU Regulation No 517/2014 of new HFC/HFO mixtures as alternatives of high GWP refrigerants in refrigeration and HVAC systems. International Journal of Refrigeration 52: 21-31. https://doi.org/10.1016/j.ijrefrig.2014.12.021

[11] In S, Cho K, Lim B, Kim H, Youn B. (2014). Performance test of residential heat pump after partial optimization using low GWP refrigerants. Appl. Ther. En. 72(2): 315-322. https://doi.org/10.1016/j.applthermaleng.2014.04. 040

[12] Mirandola A, Lorenzini E. (2016). Energy, environment and climate: From the past to the future. Int. J. of Heat $\begin{array}{llll}\text { and } & \text { Technology } & \text { 159-164. }\end{array}$ https://doi.org/10.18280/ijht.340201

[13] Montreal Protocol on substances that deplete the ozone layer, United Nation Environment Program (UN), New York, NY, USA, 1987.

[14] Kyoto Protocol to the United Nation Framework Convention on Climate Change, Kyoto, JPN, 1997.

[15] Heath EA. (2017). Amendment to the Montreal protocol on substances that deplete the ozone layer (Kigali Amendment). International Legal Materials 56(1): 193205. https://doi.org/10.1017/ilm.2016.2

[16] Aprea C, Greco A, Maiorino A, Masselli C. (2018). The drop-in of HFC134a with HFO1234ze in a household refrigerator. Int. J. of Thermal Sciences 127: 117-125. https://doi.org/10.1016/j.ijthermalsci.2018.01.026

[17] Aprea C, Greco A, Maiorino A, Masselli C, Metallo A. (2016). HFO1234yf as a drop-in replacement for R134a 
in domestic refrigerators: A life cycle climate performance analysis. International Journal of Heat and Technology 34(Special Issue 2): S212-S218. https://doi.org/10.18280/ijht.34S2

[18] Aprea C, Greco A, Maiorino A, Masselli C, Metallo A. (2016). HFO1234ze as drop-in replacement for R134a in domestic refrigerators: An environmental impact analysis. Energy Procedia 101: 964-971. https://doi.org/10.1016/j.egypro.2016.11.122

[19] Greco A, Mastrullo R, Palombo A. (1997). R407C as an alternative to R22 in vapour compression plant: an experimental study. International journal of energy research 21(12): 1087-1098. https://doi.org/10.1002/(SICI)1099114X(19971010)21:12<1087::AID-ER330>3.0.CO;2-Y

[20] Fähler S, Rößler UK, Kastner O, Eckert J, Eggeler G, Emmerich H, Entel P, Müller S, Quandt E, Albe K. (2012). Caloric effects in ferroic materials: new concepts for cooling. Adv. Eng. Mat. 14(1-2): 10-19. https://doi.org/10.1002/adem.201100178

[21] Pecharsky VK, Cui J, Johnson DD. (2016). (Magneto) caloric refrigeration: is there light at the end of the tunnel? Phil. Trans. R. Soc. A 374(2074): 20150305. https://doi.org/10.1098/rsta.2015.0305

[22] Burattini C, Nardecchia F, Bisegna F, Cellucci L, Gugliermetti F, de Lieto Vollaro A, Salata F, Golasi I. (2015). Methodological approach to the energy analysis of unconstrained historical buildings. Sustainability 7: 10428-10444. https://doi.org/10.3390/su70810428

[23] Lassandro P, Turi SD. (2017). Energy efficiency and resilience against increasing temperatures in summer: the use of PCM and cool materials in buildings. International Journal of Heat and Technology 35: S307S315. https://doi.org/10.18280/ijht.35Sp0142

[24] Pagliaro F, Cellucci L, Burattini C, Bisegna F, Gugliermetti F, de Lieto Vollaro A, Salata F, Golasi, I. (2015). A methodological comparison between energy and environmental performance evaluation. Sustainability $\quad 7$ 10324-10342. https://doi.org/10.3390/su70810324

[25] Aprea C, Greco A, Maiorino A. (2011). A numerical analysis of an active magnetic regenerative cascade system. Int. J. of Energy Research 35(3): 177-188. https://doi.org/10.1002/er.1682

[26] Aprea C, Greco A, Maiorino A, Masselli C. (2018). Magnetic refrigeration: a comparison between MnAs and $\mathrm{FeRh}$ based alloys in the room temperature range. Italian Journal of Engineering Science: Tecnica Italiana 61+1(1): 6-11. https://doi.org/10.18280/IJES.620101

[27] Aprea C, Greco A, Maiorino A. (2012). Modelling an active magnetic refrigeration system: a comparison with different models of incompressible flow through a packed bed. Applied Thermal Engineering 36: 296-306. https://doi.org/10.1016/j.applthermaleng.2011.10.034

[28] Aprea C, Greco A, Maiorino A. (2013). The use of the first and of the second order phase magnetic transition alloys for an AMR refrigerator at room temperature: a numerical analysis of the energy performances. Energy conversion and management 70: 40-55 https://doi.org/10.1016/j.enconman.2013.02.006

[29] Aprea C, Greco A, Maiorino A, Masselli C. (2018). Solid-state refrigeration: A comparison of the energy performances of caloric materials operating in an active caloric regenerator. Energy 165: 439-455. https://doi.org/10.1016/j.energy.2018.09.114

[30] Aprea C, Greco A, Maiorino A, Masselli C. (2017). A comparison between electrocaloric and magnetocaloric materials for solid state refrigeration. International Journal of Heat and Technology 35(1): 225-234. https://doi.org/10.18280/ijht.350130

[31] Aprea C, Greco A, Maiorino A, Masselli C. (2017). Analyzing the energetic performances of AMR regenerator working with different magnetocaloric materials: investigations and viewpoints. International Journal of Heat and Technology 35(Special Issue 1): S383-S390. https://doi.org/10.18280/ijht.35Sp0152

[32] Aprea C, Greco A, Maiorino A, Masselli C. (2018). Energy performances and numerical investigation of solid-state magnetocaloric materials used as refrigerant in an active magnetic regenerator. Thermal Science and $\begin{array}{llll}\text { Engineering } & \text { Progress } & \text { 370-379. }\end{array}$ https://doi.org/10.1016/j.tsep.2018.01.006

[33] Aprea C, Greco A, Maiorino A. (2015). Geo Thermag: a geothermal magnetic refrigerator. Int. J. of Refrig. 59: 75-83. https://doi.org/10.1016/j.ijrefrig.2015.07.014

[34] Aprea C, Greco A, Maiorino A, Masselli C. (2016). The energy performances of a rotary permanent magnet magnetic refrigerator. Int. J. of Refrig. 61: 1-11. https://doi.org/10.1016/j.ijrefrig.2015.09.005

[35] Aprea C, Cardillo G, Greco A, Maiorino A, Masselli C. (2016). A rotary permanent magnet magnetic refrigerator based on AMR cycle. Applied Thermal Engineering 101: 699-703. https://doi.org/10.1016/j.applthermaleng.2016.01.097

[36] Aprea C, Greco A, Maiorino A. (2017). An application of the artificial neural network to optimise the energy performances of a magnetic refrigerator. Int. J. of Refrig. 82: https://doi.org/10.1016/j.ijrefrig.2017.06.015

$238-251$.

[37] Dan'kov SY, Tishin AM, Pecharsky VK, Gschneidner Jr. KA. (1998). Magnetic phase transitions and the magneto-thermal properties of gadolinium. Phys Rev. B 57(6): https://doi.org/10.1103/PhysRevB.57.3478

[38] von Moos L, Bahl CRH, Nielsen KK, Engelbrecht K. (2015). The influence of hysteresis on the determination of the magnetocaloric effect in $\mathrm{Gd}_{5} \mathrm{Si}_{2} \mathrm{Ge}_{2}$. J. Phys. D Appl. Phys. 48: 1-7. https://doi.org/10.1088/00223727/48/2/025005

[39] Morrison K, Sandeman KG, Cohen LF, Sasso CP, Basso V, Barcza A, Katter M, Moore JD, Skokov KP, Gutfleisch O. (2012). Evaluation of the reliability of the measurement of key magnetocaloric properties: a round robin study of $\mathrm{La}(\mathrm{Fe}, \mathrm{Si}, \mathrm{Mn}) \mathrm{H} \delta$ conducted by the SSEEC consortium of European laboratories. Int. J. Refr. 35(6): 1528-1536. https://doi.org/10.1016/j.ijrefrig.2012.04.001

[40] Bjørk R, Bahl CRH, Katter M. (2010). Magnetocaloric properties of LaFe13-x-yCoxSiy and commercial grade Gd. J. Magn. Magn. Mater. 322(24): 3882-3888. https://doi.org/10.1016/j.jmmm.2010.08.013

[41] Li X, Qian XS, Lu SG, Cheng J, Fang Z, Zhang QM. (2011). Tunable temperature dependence of electrocaloric effect in ferroelectric relaxor poly (vinylidene fluoride-trifluoroethylenechlorofluoroethylene terpolymer. Appl. Phys. Lett. 99(5): 052907. https://doi.org/10.1063/1.3624533 
[42] Hamad MA. (2013). Room temperature giant electrocaloric properties of relaxor ferroelectric 0.93 PMN-0.07 PT thin film. AIP Advances 3(3): 032115. https://doi.org/10.1063/1.4795156

[43] Zhao Y, Hao X., Zhang Q. (2016). Enhanced energystorage performance and electrocaloric effect in compositionally graded $\mathrm{Pb}(1-3 / 2 \mathrm{x}) \mathrm{LaxZ} \mathrm{r} 0.85 \mathrm{Ti} 0.15 \mathrm{O} 3$. $\begin{array}{llll}\text { Ceram. Int } & \text { 42(1): }\end{array}$ https://doi.org/10.1016/j.ceramint.2015.09.122

[44] Peng B, Fan H, Zhang Q. (2013). A giant electrocaloric effect in nanoscale antiferroelectric and ferroelectric phases coexisting in a relaxor $\mathrm{Pb} 0.8 \mathrm{Ba} 0.2 \mathrm{ZrO}_{3}$ thin film at room temperature. Advanced Functional Materials 23(23): 2987-2992. https://doi.org/10.1002/adfm.201202525

[45] Zhao Y, Hao X, Zhang Q. (2015). A giant electrocaloric effect of a $\mathrm{Pb} 0.97 \mathrm{La} 0.02(\mathrm{Zr} 0.75 \mathrm{Sn} 0.18 \mathrm{Ti0.07}) \mathrm{O}_{3}$ antiferroelectric thick film at room temperature. Journal of Materials $\begin{array}{llll}\text { Chemistry } & \text { C } & 3(8) \text { : } & \text { 1694-1699. }\end{array}$ https://doi.org/10.1039/C4TC02381A

[46] Aprea C, Greco A, Maiorino A., Masselli C. (2016). A comparison between different materials in an active electrocaloric regenerative cycle with a $2 \mathrm{D}$ numerical model. International Journal of Refrigeration 69: 369382. https://doi.org/10.1016/j.ijrefrig.2016.06.016

[47] Mañosa L, Planes A, Acet M. (2013) Advanced materials for solid-state refrigeration. Journal of Materials Chemistry A 1(16): 4925-4936. https://doi.org/10.1039/b000000x

[48] Tušek J, Engelbrecht K, Millán-Solsona R, Mañosa L, Vives E, Mikkelsen LP, Pryds N. (2015). The elastocaloric effect: A way to cool efficiently. Advanced Energy Materials 5(13). https://doi.org/10.1002/aenm.201500361

[49] Gorev MV, Bogdanov EV, Flerov IN, Kocharova AG, Laptash NM. (2010). Investigation of thermal expansion, phase diagrams, and barocaloric effect in the $\left(\mathrm{NH}_{4}\right)_{2}$

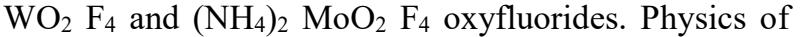
the Solid State 52(1): 167-175. https://doi.org/10.1134/S1063783410010294

[50] Wu RR, Bao LF, Hu FX, Wu H, Huang QZ, Wang J, Dong XL, Li GN, Sun JR, Shen FR, Zhao TY, Zheng XQ, Wang LC, Liu Y, Zuo WL, Zhao YY, Zhang M, Wang XC, Jin CQ, Rao GH, Han XF, Shen BG. (2015). Giant barocaloric effect in hexagonal $\mathrm{Ni}_{2}$ In-type $\mathrm{Mn}$ Co-Ge-In compounds around room temperature.

$\begin{array}{llll}\text { Scientific } & \text { Reports } & \text { 5: } & 18027 .\end{array}$ https://doi.org/10.1038/srep18027

[51] Aprea C, Greco A, Maiorino A. (2016). An experimental investigation on the substitution of HFC134a with HFO1234YF in a domestic refrigerator. Appl. Ther. En. 106: 959-967. https://doi.org/10.1016/j.applthermaleng.2016.06.098

\section{NOMENCLATURE}

$\mathrm{B}$

C

E

$\mathrm{H}$

K

$\mathrm{M}$

$\mathrm{T}$

$\mathrm{t}$

$\mathrm{u}$

$\mathrm{V}$

$\mathrm{X}$

$\mathrm{Y}$

\section{Greek symbols}

$\Delta$

$\mu$

$v$

$\tau$

\section{Subscripts}

0

1

Ad

C

$\mathrm{F}$

$\mathrm{H}$

$\mathrm{p}$ magnetic field induction, $\mathrm{T}$

specific heat, $\mathrm{J}^{\mathrm{kg}} \mathrm{kg}^{-1} \cdot \mathrm{K}^{-1}$

electric field, V.m ${ }^{-1}$

magnetic field, A. $\mathrm{m}^{-1}$

thermal conductivity, W. $\mathrm{m}^{-1} \cdot \mathrm{K}^{-1}$

magnetization, A. $\mathrm{m}^{-1}$

polarization C.m ${ }^{-2}$

pressure, $\mathrm{Pa}$

entropy, $\mathrm{J}^{\mathrm{kg}} \mathrm{kg}^{-1} \cdot \mathrm{K}^{-1}$

temperature, $\mathrm{K}$

time, $\mathrm{s}$

longitudinal fluid velocity, $\mathrm{m} . \mathrm{s}^{-1}$

orthogonal fluid velocity, $\mathrm{m} . \mathrm{s}^{-1}$

conjugate field

applied driving field

finite difference

strain

dynamic viscosity, $\mathrm{kg} \cdot \mathrm{m}^{-1} \cdot \mathrm{s}^{-1}$

cinematic viscosity, $\mathrm{m}^{2} . \mathrm{s}^{-1}$

density, kg. $\mathrm{m}^{-3}$

stress, $\mathrm{Pa}$

time period of the cycle, $\mathrm{s}$

minimum

maximum

Adiabatic

cold heat exchanger

fluid

hot heat exchanger

constant pressure

solid 